\title{
Experimental Study on the Shearing Behaviour on the Interface between Coarse Sand and Concrete under High Stress
}

\author{
Junkun Tan $\mathbb{D}^{1},{ }^{1}$ Jiaqi Guo $\mathbb{D},{ }^{2}$ Shifan Qiao, ${ }^{1}$ Changrui Dong, ${ }^{1}$ Ziyong Cai, ${ }^{1}$ \\ and Gang Wang ${ }^{1}$ \\ ${ }^{1}$ Department of Civil Engineering, Central South University, Changsha 410075, China \\ ${ }^{2}$ Department of Civil Engineering, Henan Polytechnic University, Jiaozuo 454000, China \\ Correspondence should be addressed to Jiaqi Guo; gjq@163.com
}

Received 8 March 2021; Revised 26 May 2021; Accepted 10 July 2021; Published 29 August 2021

Academic Editor: Jinze Xu

Copyright (C) 2021 Junkun Tan et al. This is an open access article distributed under the Creative Commons Attribution License, which permits unrestricted use, distribution, and reproduction in any medium, provided the original work is properly cited.

\begin{abstract}
The shear behaviour on the interface between soil and structure is a research hot point. Based on the RMT-150B rock mechanics test system, a series of high-stress direct tests were performed on the coarse sand under the condition of different moisture contents and concrete substrates with different rough and hardness. The results showed that the shear stress-displacement curve and volumetric strain-displacement curve of the interface under high stress could be fitted by a hyperbolic model; the ultimate shear strength and initial shear stiffness of the interface both increased with the normal stress while the shear stiffness decreased with the shear displacement. The crushing rate of the coarse sand particles on the interface increased with the normal stress. After the range analysis for the influencing factors of the interface's shearing behaviour, it was shown that for the ultimate shear strength, their sequence of influencing degree was normal stress, the roughness of interface, moisture content, and hardness of concrete base; for the initial shear strength, the sequence was normal stress, moisture content, interface roughness, and basal hardness. As for dry sand, the possibility of relative particle crushing was higher than that of sand with a moisture content of $8 \%$, and a peak of crushing occurred when the moisture content was $16 \%$.
\end{abstract}

\section{Introduction}

The interaction between rock-soil mass and structure is widely spread in underground engineering. Due to the difference in stiffness between the structure and the soil, problems such as nonlinearity, large deformation, and local discontinuity [1] result in a very complicated shear behaviour on the interface [2]. The shear test is the simplest method to study the mechanical properties of this interface [3]. Since Potyondy [4] adopted the direct shear apparatus, many researchers have studied the characteristics of soil and interface. Zong-Ze et al. [5] conducted large-scale direct shear tests on the interface between soil and concrete and pointed out that they slip unevenly. $\mathrm{Hu}$ and $\mathrm{Pu}[6]$ conducted a shear test on the sand using an improved direct shear apparatus and analyzed the deformation mechanism of shear failure on the interface. Suits et al. [7], Taha and Fall [8], Wang et al. [9], Xiao and Liu [10], and Farhadi and Lashkari [11] used direct shear tests to study the mechanical properties of the soil-structure interface.

In order to effectively treat the damaged underground structure and scientifically design new underground structures, it is necessary to study the shear behaviour on the interface between the underground structure and the surrounding rock soil. The force analysis and deformation calculation of the underground structure provide the basis for selecting influencing factors. Potyondy [4] studied the mechanical properties of shear on different interfaces between sand, clay, cohesive granular soil and steel, concrete, and wood through hundreds of direct shear tests. The experimental research by Fakharian and Evgin [12] shows that the volume variation and the tangential stress-strain relationship of the interface between sand and structure have a great relationship with the stress path and normal stiffness. Yang et al. [13] analyzed the friction of geogrid from several aspects such as test method, loading method, edge effect and size 


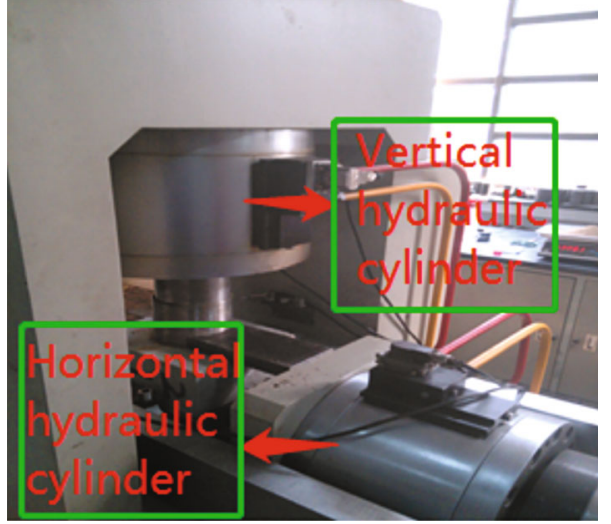

(a) Direct shear apparatus

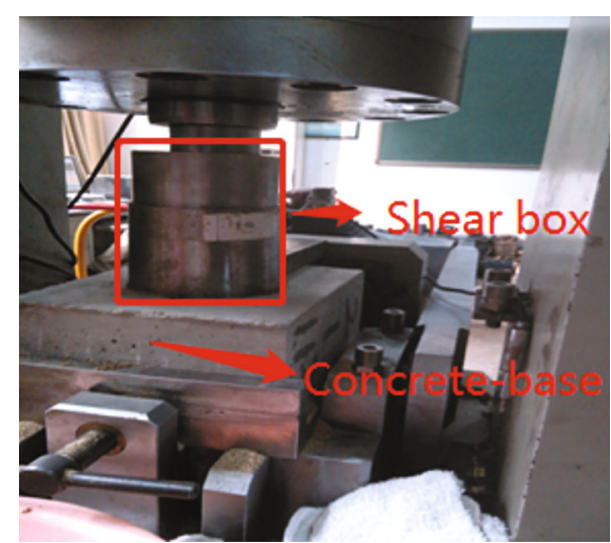

(b) Shear box

FIGURE 1: Direct shear apparatus under high stress.

effect of test box, filler thickness, compaction degree, and reinforcement clamping status characteristics affecting factors. Chen et al. [14] used a large-scale direct shear apparatus to conduct direct shear tests on the interface of red clayconcrete specimens and quantitatively analyzed the influence of roughness on the shear failure and deformation of the interface and discussed the influence mechanism of roughness. Aliyeh et al. [15] conducted direct shear tests on the interface between spherical sand and geotextile. The test revealed that the particle shape affected both the peak value and the residual friction angle. Ji et al. [16] analyzed the effects of freezing temperature, contact interface roughness, and coarse or fine aggregates on shear characteristics through the direct shear test of the frozen soil-concrete interface. $\mathrm{Li}$ et al. [17] tested the influence of temperature on the mechanical properties of the pile-red clay interface through indoor temperature-controlled direct shear tests and pointed out that the shear strength of the pile-red clay interface increased slightly with the increase of temperature. The research mentioned above has promoted the study on the interaction between soil and structure and deepened the understanding of the mechanical characteristics of the shear interaction.

With the existing projects developing toward higher and deeper trends, for example, Pingdingshan, Huainan, and Fengfeng, which have a depth of more than $600 \mathrm{~m}$, and the average depth of new mines is $500 \mathrm{~m}$, it is urgent to develop the research on shear behaviour and influencing factors of the soil-structure interface under high-stress conditions[18-23]. Guo et al. [24] designed a simple shear tester to conduct a simple shear test on the interface between saturated sand and structure and analyzed the constitutive interface model and the changing trend of interface shear stiffness under a high-stress condition. Liu et al. [25, 26] used a high-pressure direct shear instrument to study the relationship between the peak strength, residual strength, and normal stress of the interface of different structures. Lu [27] used a high normal stress residual shear instrument to systematically study the shear characteristics of the soilstructure interface with different roughness. At present, the study of shear mechanics and deformation characteristics of the interface between soil and structure under high stress is limited; the interface state evolution such as particle failure in the shear failure process was rarely involved [28-31]. Meanwhile, the influence of the relative scale of the soil particles and the surface morphology of the structural surface was rarely considered, and the understanding of the mechanism of the shear strength of the interface is still insufficient.

In this research, the RMT-150B rock test system was specially modified to conduct the high-stress shear test under four different factors: normal stress, moisture content, basal hardness, and roughness; during the test, the corresponding shear stress and shear displacement, volumetric strain and shear displacement, and particle crushing of the interface were monitored. After analyzing the test results using the intuitive analysis method, the effects of these four factors on the ultimate shear strength, initial shear stiffness, residual volume strain, initial volume strain, and relative particle crushing rate were expected to provide a reference for the study of shear mechanics and particle crushing of the interface.

\section{The Test System and Method}

2.1. The Test System. The present direct shear instruments can sustain relatively small vertical loads, but it is difficult to meet the requirements for high normal stress. So, the RMT-150B rock mechanics system was modified by specially designing and processing the accessories such as the direct shear box and the drag reduction for the slab. The modified test system can sustain the vertical load of $1000 \mathrm{kN}$, the shear load of $500 \mathrm{kN}$, and the maximum shear stroke of $20 \mathrm{~mm}$. The upper shear box is a steel cylinder with an inner diameter of $124 \mathrm{~mm}$, and the concrete base size is $250 \mathrm{~mm} \times 200 \mathrm{~mm}$ $\times 60 \mathrm{~mm}$. The test result shows that the maximum normal stress can reach more than $10 \mathrm{MPa}$. The device also has the functions of automatic loading, real-time data collection, and automatic drawing of charts. The servo-controlled hydraulic system can apply vertical and horizontal loads. There is a friction-reducing roller between the lower shear box and the main equipment to improve the accuracy of shear stress acquisition. The modified test system is shown in Figure 1. 


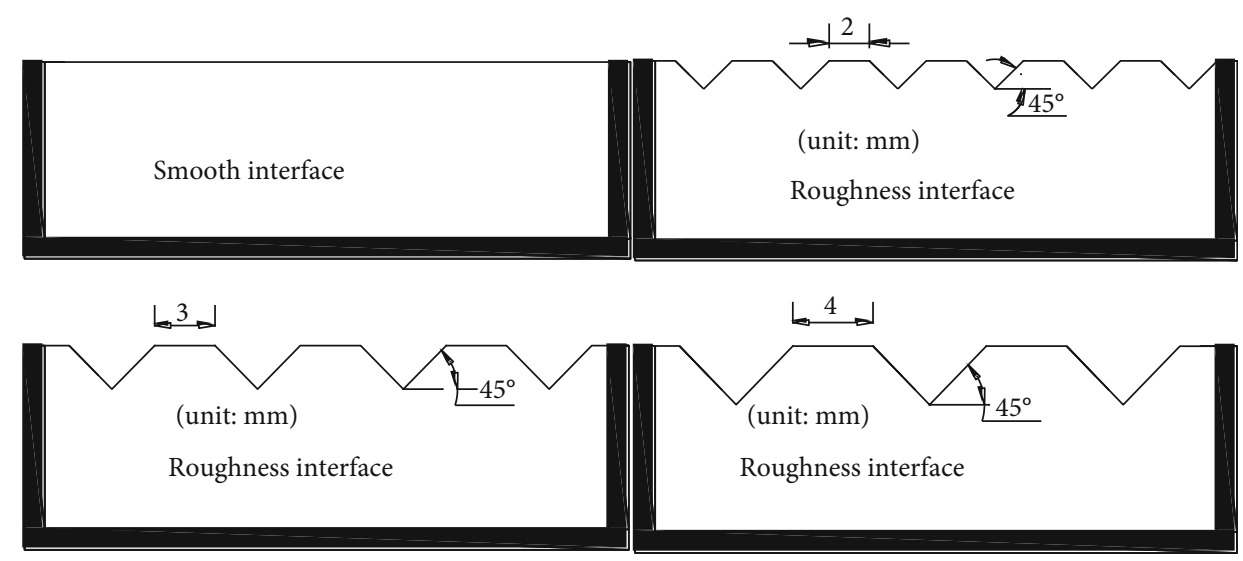

FIGURE 2: Diagram of interface.

\subsection{Identifying the Experimental Factors}

2.2.1. Roughness and Hardness of Concrete Base. The base is a concrete panel with an artificially prefabricated standard prism shape with the same height and width on the rough side. The width is $0 \mathrm{~mm}, 2 \mathrm{~mm}, 3 \mathrm{~mm}$, and $4 \mathrm{~mm}$, and the bottom angle of the isosceles trapezoidal prism is $45^{\circ}$, as shown in Figure 2.

The roughness of the substrate was calculated with the sand cone method [32], repeatedly spreading the coarse sand on the surface of the ridge structure, pouring the sand into the tray after scraping and levelling, and covering the sand with a $100 \mathrm{ml}$ graduated cylinder for 3 times. The ratio of the average value of the sand volume $v$ to the surface area of the structure $s$ is defined as the interface roughness $r$. The measured roughness is $0,0.133,0.249$, and 0.332 .

Concrete bases with four strengths of C20, C30, C40, and $\mathrm{C} 50$ are made according to the mixture ratios in the literature [33-36]. The hardness of the concrete substrate can be directly expressed by the rebound value measured by the rebound test. The strength value of the four tested concrete substrates is $28.1,33.9,38.1$, and 41.9 .

2.2.2. Coarse Sand Preparation. The particle size and characteristic parameters of coarse sand are listed in Table 1, maximum dry density of coarse sand is $1.9 \mathrm{~g} / \mathrm{cm}^{3}$, and the particle size distribution curve is shown in Figure 3. The moisture content of the sand is set as $0 \%, 8 \%, 16 \%$, and $24 \%$, respectively. The specific preparation procedure is as follows: weigh and place $1000 \mathrm{~g}$ of dried coarse sand on the tray, and then, spray the water of $0 \mathrm{~g}, 80 \mathrm{~g}, 160 \mathrm{~g}$, and $240 \mathrm{~g}$ to prepare the sand sample.

2.2.3. Normal Stress Determination. When the depth of the underground project exceeds $100 \mathrm{~m}$, the horizontal ground pressure $p$ [35] in the deep and thick soil layer is as follows:

$$
p=K H
$$

where $H$ is the depth of the buried calculation point, $m$, and $K$ is the calculation coefficient ranging from 0.01 to 0.02 .

At present, the depth of underground engineering is mostly in the range of 50 500 m. So, in this paper, the buried
TABle 1: Characteristic size and parameters.

\begin{tabular}{lcccccc}
\hline Property & $\mathrm{d} 60$ & $\mathrm{~d} 50$ & $\mathrm{~d} 30$ & $\mathrm{~d} 10$ & $\mathrm{Cu}$ & $\mathrm{Cc}$ \\
Coarse sand $(\mathrm{mm})$ & 0.464 & 0.430 & 0.263 & 0.089 & 5.21 & 1.675 \\
\hline
\end{tabular}

depths are set as $100 \mathrm{~m}, 200 \mathrm{~m}, 300 \mathrm{~m}$, and $400 \mathrm{~m}$, and the corresponding coefficient $K$ is 0.2 . The normal stress of the interface is calculated as $2 \mathrm{MPa}, 4 \mathrm{MPa}, 6 \mathrm{MPa}$, and $8 \mathrm{MPa}$ using Equation (1).

2.3. The Test Scheme. Four factors affecting the shear behaviour of interfaces under high stress, including concrete basal hardness, interface roughness, normal stress, and soil moisture content, are selected, and 4 levels of each influencing factor are designed, as shown in Table 2.

Before conducting the shear test, the coarse sand sample was firstly loaded in the vertical direction at a rate of $0.5 \mathrm{kN} / \mathrm{s}$; then, the consolidation was carried out under a specific normal load at the rate of $0.0025 \mathrm{~mm} / \mathrm{min}$; after about $3 \mathrm{~min}$, the consolidation became stable; the shear test started at a rate of $0.02 \mathrm{~mm} / \mathrm{s}$ under a constant normal load. When the shear stress-displacement curve became flat or the shear displacement reached $12 \mathrm{~mm}$, the test would be terminated. At the same time, the shear stress, relative shear displacement, and normal specimen displacement of the interface were recorded.

\section{Results and Analysis of Shear Test}

3.1. The Curve of Shear Stress-Displacement. The curve of shear stress-displacement on the interface between the coarse sand and the structure under high stress is shown in Figure 4.

It can be seen that under the condition of different concrete basal hardness, the curve of shear stress-displacement was the same, and the normal stress showed an obvious influence on the curve. The shear strength and shear stiffness increased with the normal stress. When the normal stress was $2 \mathrm{MPa}$, the shear stress-displacement curve showed an ideal plastic property. When the normal stress was greater than or equal to $4 \mathrm{MPa}$, because the broken coarse sand particles were relatively stable and the void ratio almost did not change when normal stress was $2 \mathrm{MPa}$, the curve showed the 


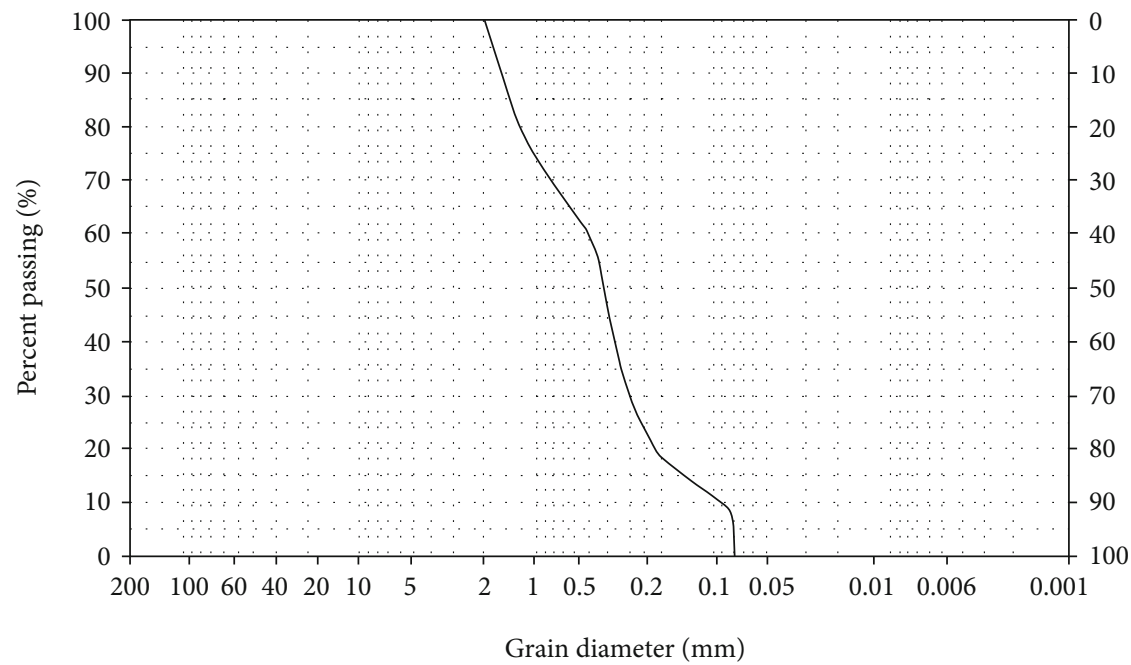

FIgURE 3: Particle size distribution curve.

TABLE 2: Selected test factors.

\begin{tabular}{lccc}
\hline $\begin{array}{l}\text { Normal stress } \\
(\mathrm{A})(\mathrm{MPa})\end{array}$ & $\begin{array}{c}\text { Roughness } \\
(\mathrm{B})(\mathrm{mm})\end{array}$ & $\begin{array}{c}\text { Basal hardness (C) } \\
\left(\mathrm{N} / \mathrm{mm}^{2}\right)\end{array}$ & $\begin{array}{c}\text { Moisture } \\
\text { content } \\
(\mathrm{D})(\%)\end{array}$ \\
\hline $2(\mathrm{~A} 1)$ & $0.083(\mathrm{~B} 1)$ & $28.1(\mathrm{C} 1)$ & $0(\mathrm{D} 1)$ \\
$4(\mathrm{~A} 2)$ & $0.133(\mathrm{~B} 2)$ & $33.9(\mathrm{C} 2)$ & $8(\mathrm{D} 2)$ \\
$6(\mathrm{~A} 3)$ & $0.249(\mathrm{~B} 3)$ & $38.1(\mathrm{C} 3)$ & $16(\mathrm{D} 3)$ \\
$8(\mathrm{~A} 4)$ & $0.332(\mathrm{~B} 4)$ & $41.9(\mathrm{C} 4)$ & $24(\mathrm{D} 4)$ \\
\hline
\end{tabular}

phenomenon of strain hardening. According to the principle of the relationship between density and shear strength [36], the shear strength tends to be a stable value. When the normal stress was greater than or equal to $4 \mathrm{MPa}$, with the increase of the shear displacement, the density and the shear strength, and the decrease of the void ratio, the number of broken sand particles all increased. In the highstress direct shear test, the relationship between shear stress and displacement was not corresponding to the shape of the hyperbolic model, and the initial shear stiffness of the interface was affected by various factors regarding the interface.

3.2. Regression Analysis of Test Data. The nonlinear hyperbolic model $\tau=w_{\mathrm{s}} /\left(a w_{\mathrm{s}}+b\right)$ can be transformed into a linear regression model $w_{\mathrm{s}} / \tau=a w_{\mathrm{s}}+b$ [37], where $w_{\mathrm{s}}$ is the shear displacement and $a$ and $b$ are the model regression parameters. The transformed hyperbolic linear regression model was used to perform regression analysis on the shear test data, as shown in Table 3.

It can be known that the hyperbolic model was used to perform regression analysis on the $\tau-s$ relationship. The regression coefficient $R$ was more than 0.97 , indicating that a hyperbolic model can well describe the interface shear stress-displacement and volumetric strain-shear under the high stress.
According to the $\tau-s$ hyperbolic model, the ultimate shear strength $\tau_{\mathrm{u}}$ on the interface can be obtained:

$$
\tau_{\mathrm{u}}=\lim _{w_{\mathrm{s}} \longrightarrow \infty} \frac{w_{\mathrm{s}}}{a w_{\mathrm{s}}+b}=\frac{1}{a} .
$$

The slope of the curve of shear stress-displacement was regarded as the shear stiffness $k_{\text {st }}$ of the interface:

$$
k_{\mathrm{st}}=\frac{\partial \tau}{\partial w_{\mathrm{s}}}=\frac{b}{\left(a w_{\mathrm{s}}+b\right)^{2}} .
$$

When the shear displacement approached 0 , the shear stiffness became the initial value of $k_{\mathrm{si}}$ :

$$
k_{\mathrm{si}}=\lim _{w_{\mathrm{s}} \longrightarrow \infty}\left(\frac{\partial \tau}{\partial w_{\mathrm{s}}}\right)=\frac{1}{b} .
$$

Two regression parameters $a$ and $b$ can be calculated through Equations (2) and (4), as listed in Table 4. The ultimate shear strength and initial shear stiffness of the interface under high stress are listed in Table 5.

3.3. Crushing Mechanism of the Particle on the Interface and the Determination of the Thickness of the Shear Zone. Particle crushing mainly occurred in a thin layer near the interface, and the thickness is equal to that of the shear zone. There are two forms of particle crushing on the interface under high-stress compression and shearing. Due to the difference in the size of the coarse sand particle, when the particles are compressed, the larger particles will play the role of the skeleton and sustaining most of the normal pressure, and the smaller particles are embedded between the skeletons and consume the rest of the normal pressure. So the local edges and corners of the large-diameter particles will be damaged, or the whole particle is crushed to smaller-sized particles to help resist normal pressure. When the larger normal stress is applied, the particles will break down again and became a 

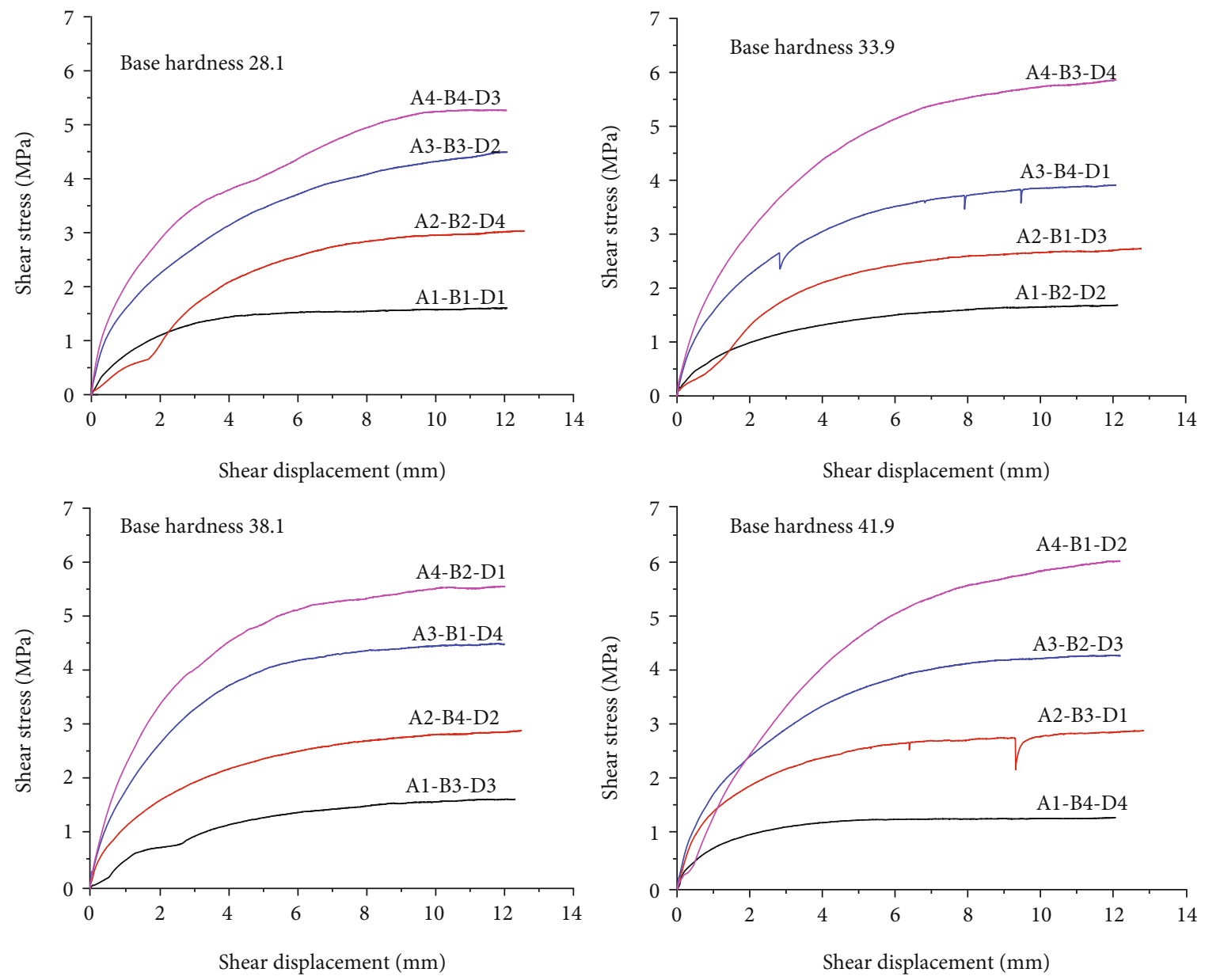

FIGURE 4: Shear stress-shear displacement curves under different test schemes.

TABLE 3: Regression results of experimental data.

\begin{tabular}{lccc}
\hline Conditions & $a\left(\mathrm{MPa}^{-1}\right)$ & $b(\mathrm{~mm} / \mathrm{MPa})$ & Regression factors $R$ \\
\hline A2-B1-C2-D0 & 0.689 & 0.554 & 0.988 \\
A4-B2-C2-D24 & 1.167 & 0.217 & 0.971 \\
A6-B3-C2-D8 & 0.520 & 0.181 & 0.992 \\
A8-B4-C2-D16 & 0.392 & 0.155 & 0.987 \\
A2-B2-C3-D8 & 0.978 & 0.508 & 0.997 \\
A4-B1-C3-D16 & 0.896 & 0.280 & 0.974 \\
A6-B4-C3-D0 & 0.439 & 0.215 & 0.995 \\
A8-B3-C3-D24 & 0.360 & 0.137 & 0.997 \\
A2-B3-C4-D16 & 1.656 & 0.458 & 0.993 \\
A4-B4-C4-D8 & 0.640 & 0.291 & 0.996 \\
A6-B1-C4-D24 & 0.353 & 0.186 & 0.993 \\
A8-B2-C4-D0 & 0.284 & 0.152 & 0.997 \\
A2-B4-C5-D24 & 0.561 & 0.701 & 0.989 \\
A4-B3-C5-D8 & 0.394 & 0.316 & 0.992 \\
A6-B2-C5-D16 & 0.403 & 0.195 & 0.995 \\
A8-B1-C5-D8 & 0.531 & 0.117 & 0.993 \\
\hline
\end{tabular}

smaller size to form a new compressive crushing balance, and the crushing rate increases as the normal stress increases. At the same time, the coarse sand particles at the shear zone and the interface will be clamped and rotated and be subjected to an antirotation resistance from the surrounding particles. So, when the shear strength of the particle itself was less than the clamping force, particles will undergo shear failure under counterrotating force. Liu and $\mathrm{Lu}$ [38] pointed out that shear stress is an essential factor to determine particle crushing. The particle and the interface mainly exist in the form of point contact. The higher the normal stress, the closer the bite between the particles and the interface, the more difficult it is for the particles to slip and roll, resulting in the increase of horizontal shear failure of the particles.

Based on previous research on the thickness of the interface, the average soil particle size d50 can reflect the phenomenon of rotation, self-locking, adjustment, and the potential ability to break up [39]. Hence, the recommended thickness of the interface is also mainly related to the average particle size d50. Desai and Ma [37] believed that the shearing and fragmentation of particles on the interface between soil and structure occurred near the interface. Frost et al. [40] used digital photography technology to microscopically determine the thickness of the interface as (5 7) d50. Wang et al. [41] 
TABLE 4: Intuitive analysis results of shear strength.

\begin{tabular}{|c|c|c|c|c|}
\hline Factors & $\begin{array}{c}\text { Normal pressure } \\
\text { A }\end{array}$ & $\begin{array}{l}\text { Roughness } \\
\text { B }\end{array}$ & $\begin{array}{c}\text { Basal hardness } \\
\text { C }\end{array}$ & $\begin{array}{c}\text { Moisture content } \\
\text { D }\end{array}$ \\
\hline$K_{1}$ & 1.562 & 3.708 & 3.604 & 3.494 \\
\hline$K_{2}$ & 2.896 & 3.641 & 3.549 & 3.77 \\
\hline$K_{3}$ & 4.294 & 3.728 & 3.650 & 3.483 \\
\hline$K_{4}$ & 5.675 & 3.350 & 3.624 & 3.677 \\
\hline$R$ & 4.113 & 0.378 & 0.101 & 0.278 \\
\hline Optimization levels & 4 & 1 & 3 & 4 \\
\hline Important order & \multicolumn{4}{|c|}{ Normal pressure $\mathrm{A}>$ roughness $\mathrm{B}>$ moisture content $\mathrm{D}>$ basal hardness $\mathrm{C}$} \\
\hline Optimal combination & \multicolumn{4}{|c|}{$\mathrm{A} 4 \mathrm{~B} 1 \mathrm{C} 3 \mathrm{D} 4$} \\
\hline
\end{tabular}

TABLE 5: Ultimate shear strength and initial shear stiffness.

\begin{tabular}{|c|c|c|c|c|c|c|c|}
\hline \multirow{2}{*}{ Cases } & \multicolumn{5}{|c|}{ Factors } & \multirow{2}{*}{$\begin{array}{l}\text { Ultimate shear } \\
\text { strength }(\mathrm{MPa})\end{array}$} & \multirow{2}{*}{$\begin{array}{c}\text { Initial shear } \\
\text { stiffness }\end{array}$} \\
\hline & A & B & C & $\mathrm{D}$ & $\mathrm{E}$ & & \\
\hline 1 & A1 & B1 & $\mathrm{C} 1$ & D1 & E1 & 1.604 & 1.451 \\
\hline 2 & A1 & B2 & $\mathrm{C} 2$ & D2 & $\mathrm{E} 2$ & 1.687 & 1.022 \\
\hline 3 & A1 & B3 & $\mathrm{C} 3$ & D3 & E3 & 1.644 & 0.604 \\
\hline 4 & A1 & B4 & $\mathrm{C} 4$ & D4 & $\mathrm{E} 4$ & 1.314 & 1.783 \\
\hline 5 & A2 & $\mathrm{B} 1$ & $\mathrm{C} 2$ & D3 & $\mathrm{E} 4$ & 2.737 & 1.115 \\
\hline 6 & A2 & B2 & $\mathrm{C} 1$ & D4 & E3 & 3.040 & 0.856 \\
\hline 7 & A2 & B3 & $\mathrm{C} 4$ & D1 & E2 & 2.904 & 2.536 \\
\hline 8 & A2 & B4 & $\mathrm{C} 3$ & D2 & E1 & 2.903 & 1.562 \\
\hline 9 & A3 & $\mathrm{B} 1$ & $\mathrm{C} 3$ & D4 & $\mathrm{E} 2$ & 4.492 & 2.827 \\
\hline 10 & A3 & B2 & $\mathrm{C} 4$ & D3 & E1 & 4.276 & 2.484 \\
\hline 11 & A3 & B3 & $\mathrm{C} 1$ & D2 & $\mathrm{E} 4$ & 4.499 & 1.922 \\
\hline 12 & A3 & B4 & $\mathrm{C} 2$ & D1 & E3 & 3.908 & 2.276 \\
\hline 13 & A4 & B1 & $\mathrm{C} 4$ & D2 & E3 & 6.001 & 1.884 \\
\hline 14 & A4 & B2 & $\mathrm{C} 3$ & D1 & $\mathrm{E} 4$ & 5.561 & 3.512 \\
\hline 15 & A4 & B3 & $\mathrm{C} 2$ & D4 & E1 & 5.864 & 2.773 \\
\hline 16 & A4 & B4 & $\mathrm{C} 1$ & D3 & E2 & 5.273 & 2.547 \\
\hline
\end{tabular}

analyzed the two-dimensional discrete element method and found that the maximum thickness of the shear zone at the interface was (8-10) $\mathrm{d} 50$. By microscopically observing the direct shear test, Zhang [42] found that the thickness of the coarse-grained soil and the structural shear zone was about (5-6) d50; the roughness of the structural panel and the normal stress had little effect on the thickness of the shear zone. In this paper, to guarantee the quality of this research, the thickness of the interface shear zone was set as the maximum value (10) $\mathrm{d} 50$. The average particle size of the coarse sand used in the interface shear test was $\mathrm{d} 50=0.43 \mathrm{~mm}$, and the corresponding thickness of the face shear band was set as $4.30 \mathrm{~mm}$ under high stress. In order to ensure the consistency of the sampling thickness, upper and lower shear boxes that can be embedded were designed, as shown in Figure 5. The bottom of the lower shear box is in contact with the concrete interface, and its height is consistent with the thickness of the selected shear band. The upper shear box can be completely removed to carry out smoothing, sampling, and screening.

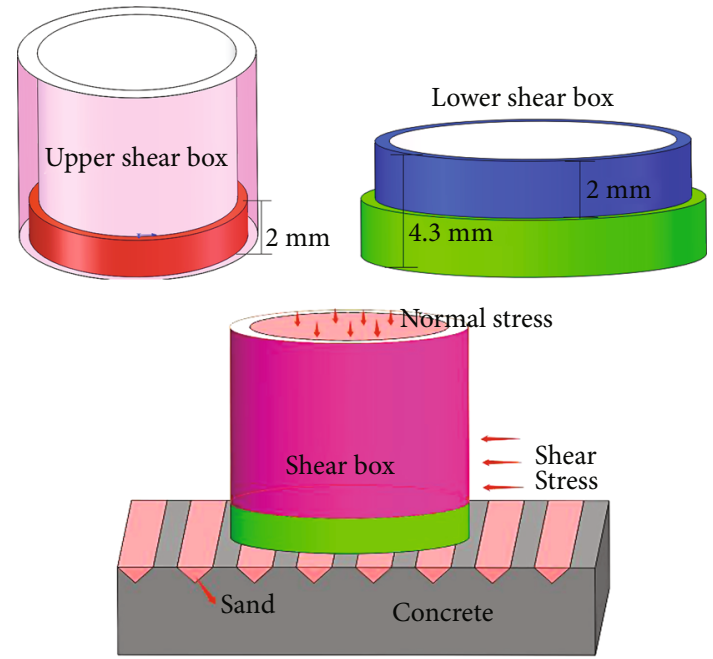

FIGURE 5: Layered shear box. 


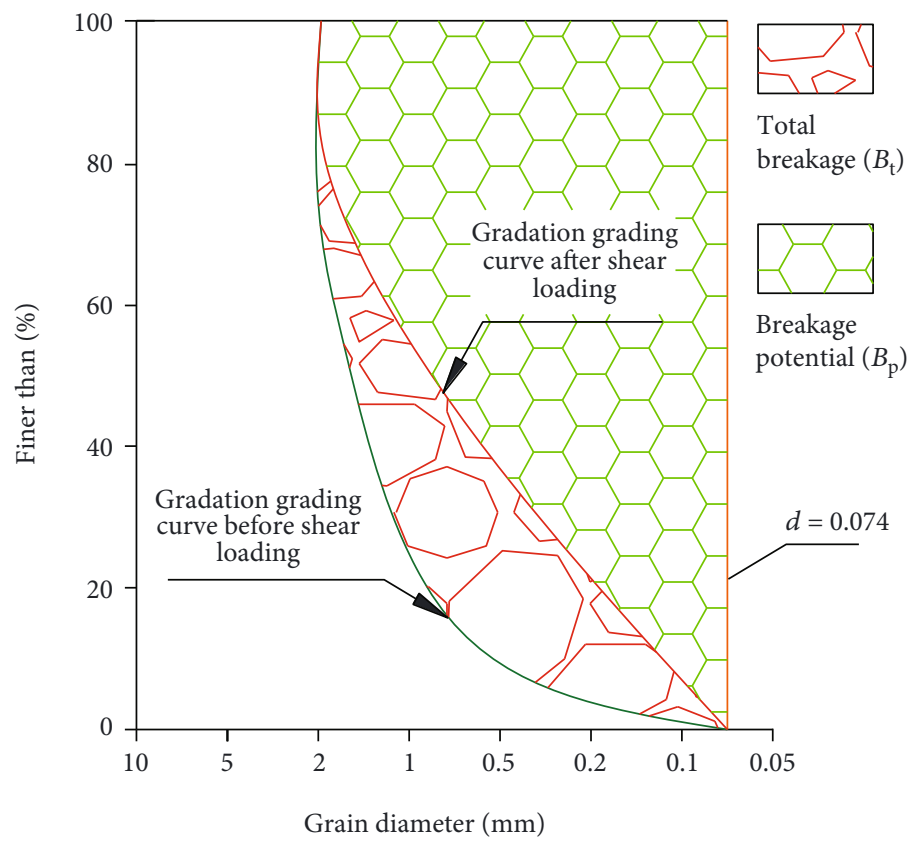

Figure 6: Definition of relative crushing $\left(B_{\mathrm{r}}\right)$.

3.4. Evaluation Method and Selection of Particle Crushing. As for the particle crushing degree, it is necessary to select a reasonable quantitative indicator. Lade et al. [43] proposed that the change value (B10) of the limited particle size d10 after the test could be used to characterize the crushing degree of particle. This index is greatly affected by the particle size, and it is difficult to reflect each particle group and the actual change amount. Hardin [44] proposed the changing area which is enclosed by the particle analysis curves, and the vertical line $d=0.074 \mathrm{~mm}$ was regarded as the total broke $B_{\mathrm{t}}$; the area enclosed by the vertical line $d=0.074 \mathrm{~mm}$ and the particle analysis curve before the test was considered as the crushing potential $B_{\mathrm{p}}$, as shown in Figure 6:

$$
B_{\mathrm{r}}=\frac{B_{\mathrm{t}}}{B_{\mathrm{p}}}
$$

Hardin's research showed that when only particle gradation was changed, the relative crushing $B_{\mathrm{r}}$ was constant and independent of gradation. $B_{\mathrm{r}}$ can be used as an index to evaluate particle crushing, and some problems of particle crushing can be discussed.

3.5. The Relationship between Particle Crushing and Influencing Factors. By using the evaluation method for particle crushing above, data processing software was applied to process the particle crushing test data to obtain the curve of normal stress-relative crushing rate, as shown in Figure 7.

There are many factors affecting the crushing of coarse sand particles on the interface during shear deforming. Therefore, the relationship between the relative crushing rate and the normal stress shows a large dispersion. According to Figure 8 , it can be seen that the normal stress $(2 \mathrm{MPa} \sim 8 \mathrm{MPa})$ affected the relative crushing rate of the coarse sand on the interface following laws: (1) the relative crushing rate increased with the increase of normal stress and presented a nonlinear increase in the opening upward. Compared with the moisture content, basal hardness, and roughness, the influence of normal stress was more significant. (2) When the moisture content was $0 \%$, the relative particle crushing increased rapidly with the normal stress; for the same normal stress, the relative particle crushing rate first increased and then decreased with the increase of moisture content; the most severe particle crushing appeared when the rate was $16 \%$. As the moisture content further increased, the relative particle crushing decreased. (3) The impact of basal hardness and interface roughness on particle crushing was relatively discrete.

\section{Analysis of Factors on the Shear Characteristics of the Interface}

4.1. Analysis of Influence Factors of Ultimate Shear Strength. To determine the degree of various factors' influence on the ultimate shear strength of the interface, range analysis was carried out on the orthogonal table test data, as listed in Table $4 . K$ is the average value of test results for different levels of each factor, and it can be used to choose the optimal value of every factor to make the optimal test design; $R$ is the range of factors, and the range of test results can be shown through the range response. The larger the $R$, the greater the influence of this factor on the test index, which should be regarded as the main factor. According to Table 4, it can be analyzed that the sequence of factors' influence is normal stress, interface roughness, moisture content, and concrete basal hardness; the optimal combination of the test was determined as $\mathrm{A} 4 \mathrm{~B} 1 \mathrm{C} 3 \mathrm{D} 4$, meaning the ultimate shear strength of the interface reached the maximum under the 


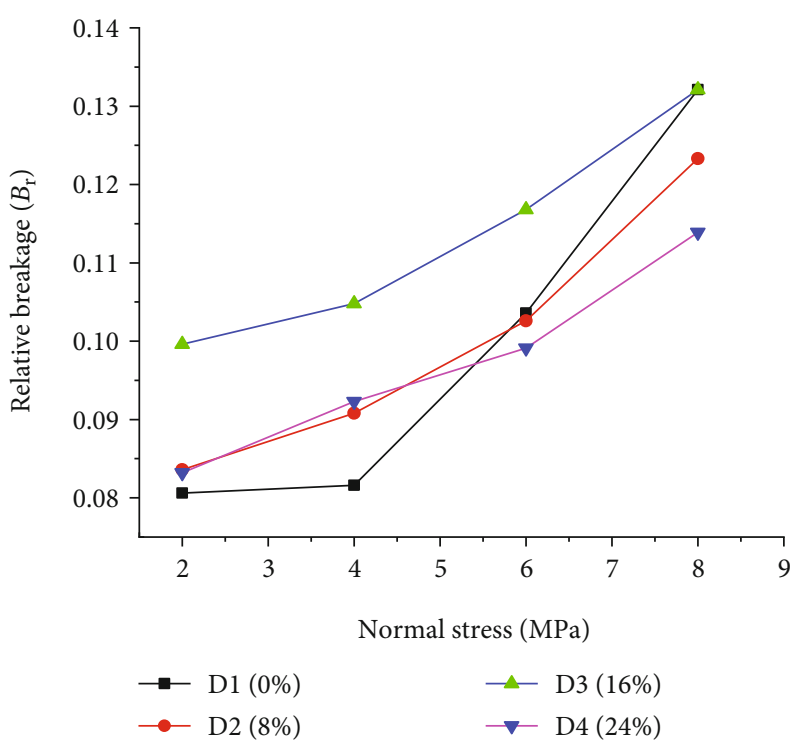

(a)

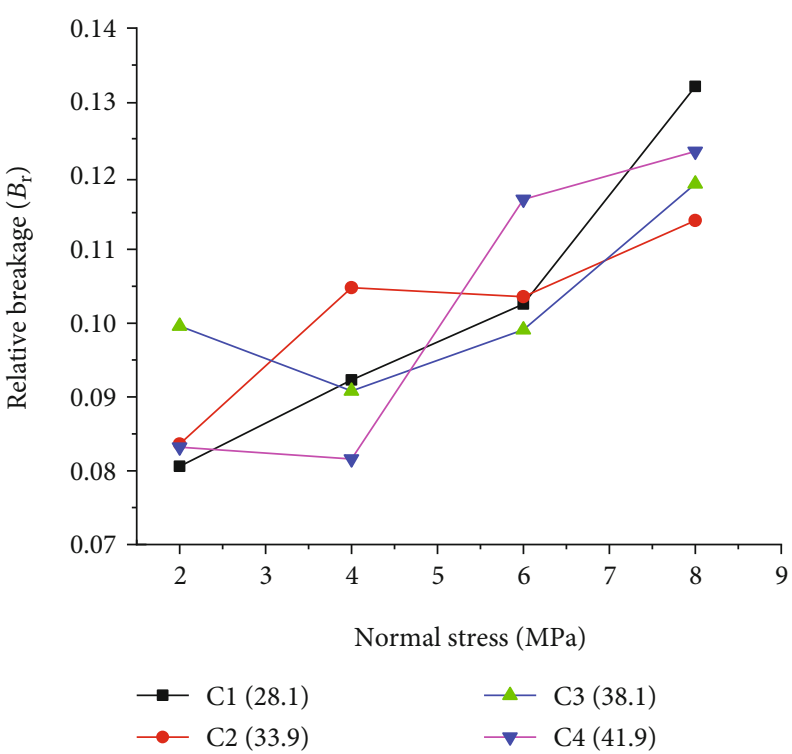

(b)

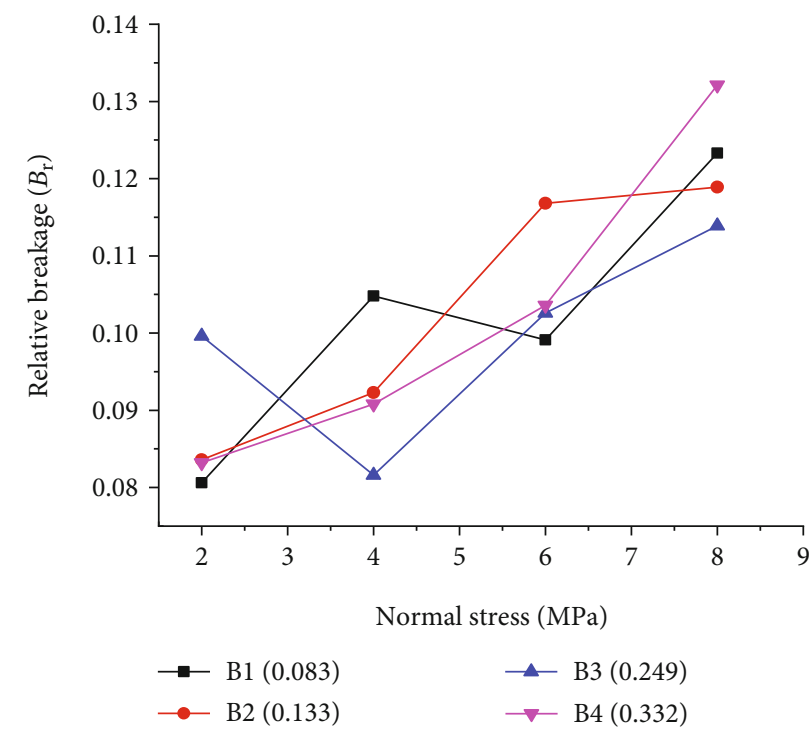

(c)

FIGURE 7: Relationship between relative crushing and normal stress.

combination of normal stress of $8 \mathrm{MPa}$, the roughness of 0.083 , moisture content of $24 \%$, and basal hardness of 38.1 .

In order to make up the disadvantage of insufficient exploration of the relationship between the variation of factors and ultimate shear strength in the range analysis, the test data was analyzed to estimate the influence of each factor qualitatively, and the results are shown in Figure 9.

According to Figure 9, the ultimate shear strength of the interface increased approximately linearly with normal stress. According to the Mohr-Coulomb criterion, the ultimate shear strength of noncohesive soil is related to the normal stress and the internal angle of friction. The internal friction angle remains unchanged, and the shear strength is proportional to the normal stress. As the roughness of the interface increased, the ultimate shear strength first increased and then decreased; this is because when the rough surface was small, the sand particles and the interface moved in a sliding manner and the binding force was small. As the roughness of the interface increased, the groove width became close to the grain size of the coarse sand, and the particles and the interface were inlaid, which hindered the movement of the particles. As the ultimate shear strength increased, the roughness furtherly increased, the shear stress of the interface was smaller, and the ultimate shear strength was reduced accordingly; the hardness and moisture content of the base hardly affected the ultimate shear strength.

It can be concluded that the ultimate shear strength of the interface was the largest under the conditions of high normal stress, small roughness, low dry density, medium basal hardness, and high moisture content. 


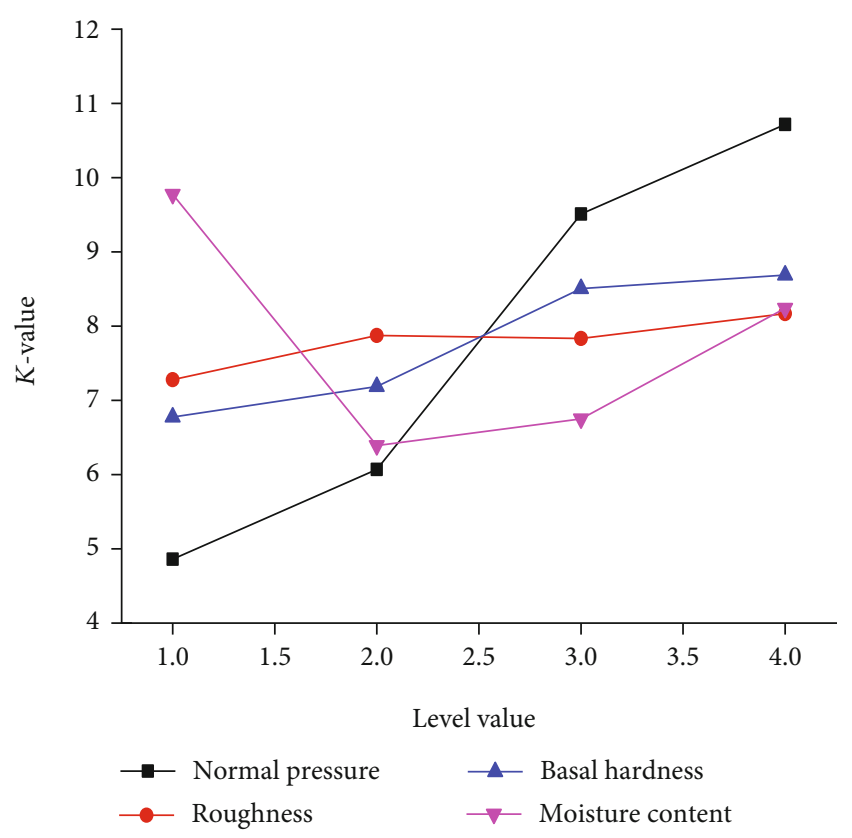

FIGURE 8: Relationship between the initial shear stiffness and the influence of factors.

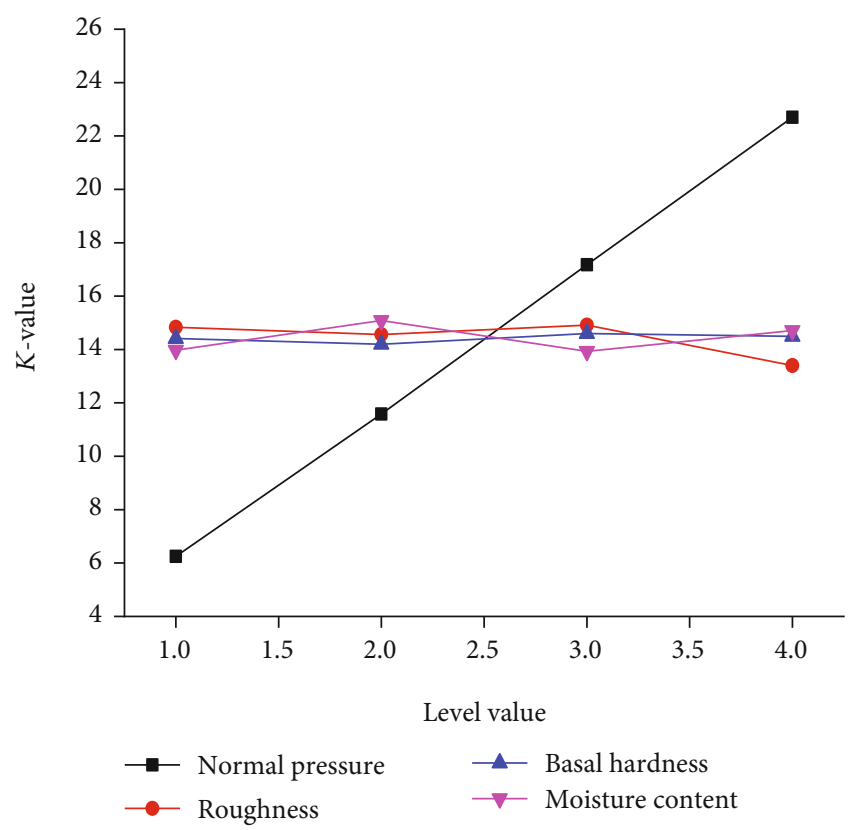

FIGURE 9: Relationship between shear strength and influencing factors.

4.2. Analysis of Influence Factors of Initial Shear Stiffness of the Interface. To determine the influence degree, the optimal combination, and the order of effects on the initial shear strength, a range analysis was performed on the orthogonal table test data. The analysis results are shown in Table 6.

It can be seen that the factors affecting the ultimate shear strength in descending order are normal stress, basal hardness, moisture content, and roughness. The optimal combination of the test is A4B4C4D1, in which the ultimate shear stiffness of the interface between coarse sand and concrete was the largest when the normal stress was $8 \mathrm{MPa}$; the combination is the roughness of 0.332 , moisture content of $0 \%$, and basal hardness of 41.9.

According to Figure 8, by visually analyzing the experimental data, it was found that the initial shear stiffness increased nonlinearly with the increase of normal stress; this is because, at the initial stage of shearing, the shear energy is proportional to the normal pressure. However, under different normal stress, the adjustment of the friction angle of the interface and the crushing of coarse sand particles is different, causing the normal stress and the initial shear stiffness to increase nonlinearly. With the increase of the moisture content, the initial shear stiffness first increased and then decreased, and the minimum value was found when the moisture content was between $8 \%$ and $16 \%$. Due to the low crushing strength of dry sand, the density of coarse sand and the shear resistance between the coarse sand and concrete structure were increased. As the moisture content increased, the water film between the soil particles appeared "adsorption." The water film between the particles sustained part of the force, and the crushing strength of the coarse sand gradually increased, reducing the amount of particle crushing. However, when the moisture content continued to increase, the "adsorption" effect of the water film gradually decreased and disappeared. At this time, the crushing strength of the coarse sand gradually decreased [45], which means there existed an optimal moisture content, and the crushing strength reached the maximum value. The literature [46] pointed out that under the same normal stress, the skeleton curve under different moisture contents existed a critical moisture content which was proved to be $11.2 \%$. The shear strength increased with the increase of the base hardness; the roughness of the interface had little effect on the ultimate shear stress, which showed a slight increase with the increase of the roughness.

4.3. Visual Analysis of Particle Crushing on the Interface. In order to determine the optimal level, optimal combination, and priority order of the initial shear strength, the range analysis of the orthogonal table test data was carried out. The analysis results are shown in Table 7 .

According to Table 7 , it can be seen that the influence degree of the factors on the ultimate shear strength in descending order is normal stress, basal hardness, moisture content, and roughness. The optimal combination of the test is $\mathrm{A} 4 \mathrm{~B} 1 \mathrm{C} 1 \mathrm{D} 3$, which means the normal stress is $8 \mathrm{MPa}$, the roughness is 0.083 , the moisture content is $16 \%$, and the basal hardness is 28.1. The particle crushing of the interface between the coarse sand and the concrete is the most serious.

According to Figure 10, it can be seen that the relative crushing of concrete particles increased with the increase of the normal stress. When the normal stress was $4 \mathrm{MPa}$ $8 \mathrm{MPa}$, the relative crushing increment of the normal stress was significantly larger than that of $2 \mathrm{Mpa}-4 \mathrm{MPa}$. As for the dry sand with $0 \%$ moisture content, its relative particle crushing rate was higher than the sand with $8 \%$ moisture content. When the moisture content was $16 \%$, the crushing peak occurred and then weakened; the particles were gradually 
TABLE 6: Intuitive analysis results of shear strength.

\begin{tabular}{|c|c|c|c|c|}
\hline Factors & $\begin{array}{c}\text { Normal pressure } \\
\text { A }\end{array}$ & $\begin{array}{c}\text { Roughness } \\
\text { B }\end{array}$ & $\begin{array}{c}\text { Basal hardness } \\
\text { C }\end{array}$ & $\begin{array}{c}\text { Moisture content } \\
\text { D }\end{array}$ \\
\hline$\overline{K_{1}}$ & 1.215 & 1.820 & 1.694 & 2.444 \\
\hline$K_{2}$ & 1.517 & 1.968 & 1.796 & 1.598 \\
\hline$K_{3}$ & 2.377 & 1.959 & 2.126 & 1.687 \\
\hline$K_{4}$ & 2.6789 & 2.042 & 2.172 & 2.060 \\
\hline$R$ & 1.463 & 0.223 & 0.478 & 0.846 \\
\hline Optimization levels & 4 & 4 & 4 & 1 \\
\hline Important order & \multicolumn{4}{|c|}{ Normal pressure $\mathrm{A}>$ basal hardness $\mathrm{C}>$ moisture content $\mathrm{D}>$ roughness $\mathrm{B}$} \\
\hline Optimal combination & \multicolumn{4}{|c|}{$\mathrm{A} 4 \mathrm{~B} 4 \mathrm{C} 4 \mathrm{D} 1$} \\
\hline
\end{tabular}

TABLE 7: Visual analysis of shear particle crushing rate on the interface.

\begin{tabular}{lcccc}
\hline Factors & $\mathrm{A}$ & $\mathrm{B}$ & $\mathrm{C}$ & $\mathrm{D}$ \\
\hline$K_{1}$ & 0.086 & 0.114 & 0.120 & 0.114 \\
$K_{2}$ & 0.092 & 0.108 & 0.101 & 0.100 \\
$K_{3}$ & 0.106 & 0.101 & 0.109 & 0.120 \\
$K_{4}$ & 0.111 & 0.104 & 0.096 & 0.092 \\
$R$ & 0.029 & 0.013 & 0.024 & 0.028 \\
Optimization levels & 4 & 1 & 1 & 3 \\
Important order & Normal pressure A > basal hardness C \\
Optimal combination & $>$ moisture content D > roughness B \\
\hline
\end{tabular}

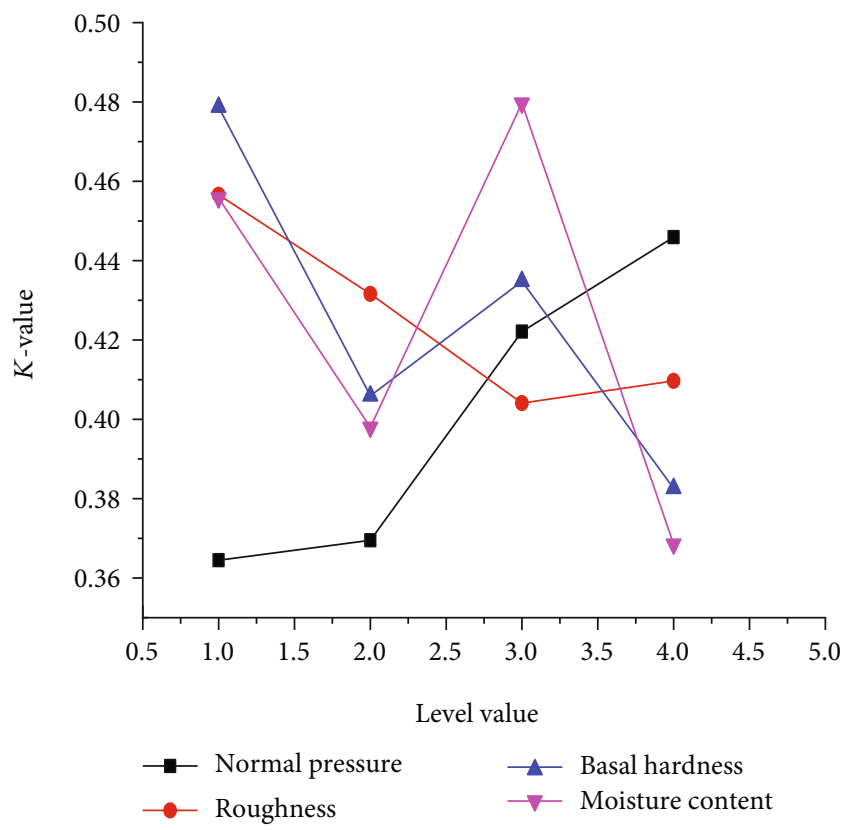

FIgURE 10: Relationship between particle crushing rate and influencing factors. broken with the increase of interface roughness and basal hardness, and all of them presented a decreasing trend.

By analyzing the above factors, the initial shear strength, ultimate shear strength, and particle breaking rate are affected by the stress method; the largest deeply buried in the soil and concrete interface engineering should fully consider the influence of buried depth, for deep pile vertical mine shaft wall, and other projects necessary from the concrete surface coarse degree to adjust the interface shear strength limit and to avoid the uneven settlement of stratum soil resulting in the structure extrusion damage.

\section{Conclusions}

(1) A shear device for the high-stress shear test of the interface was designed. It can be obtained that the ultimate shear strength under high stress increased with the increase of normal stress, and the shear stiffness of interface increased with the shear displacement; when the normal stress was $2 \mathrm{MPa}$, the shear stress-shear displacement curve presented ideal plasticity. When the normal stress was greater than or equal to $4 \mathrm{MPa}$, the curve showed strainhardening characteristics. Both the shear stressshear displacement curve and the volumetric strain-shear displacement curve can be described using the hyperbolic model

(2) The initial shear stiffness of the coarse sand and the interface showed a linear relationship with the normal stress; the initial shear stiffness showed an obvious increasing trend with the increase of the interface roughness and the basal hardness. Under the combination of normal stress of $8 \mathrm{MPa}$, the roughness of 0.083 , moisture content of $24 \%$, and basal hardness of 38.1, the ultimate shear strength test of the interface between coarse sand and concrete reached the maximum

(3) The ultimate shear strength of the interface was most affected by the normal stress, and the relationship between the shear strength and the normal pressure was relatively linear. Followed by the roughness of 
the interface, the influence degree of the moisture content was slightly greater than the strength of the concrete interface. When the normal stress was $8 \mathrm{MPa}$, the roughness was 0.332 , the moisture content was $0 \%$, and the basal hardness was 41.9 , the ultimate shear stiffness of the interface between the coarse sand and the concrete reaches the highest

(4) The relative crushing rate of coarse sand increased with the increase of normal stress, and the relationship between relative crushing and normal stress presented a nonlinear increase in the opening upward. Normal stress had the most obvious influence on the shear fracture strength of the interface, followed by the interface's roughness. The hardness and moisture content of the substrate had a weaker effect on the shear fracture of the interface of the structure

\section{Data Availability}

The data used to support the findings of the study are available from the corresponding author upon request.

\section{Conflicts of Interest}

The authors declare that they have no conflicts of interest.

\section{Acknowledgments}

The research work described in this paper was supported by a project from the National Natural Science Foundation of China (51778215) and the key projects of the Science and Technology Department of Henan Province (152102210318).

\section{References}

[1] S. Y. Peng, C. W. W. Ng, and G. Zheng, "The dilatant behaviour of sand-pile interface subjected to loading and stress relief," Acta Geotechnica, vol. 9, no. 3, pp. 425-437, 2014.

[2] C. W. Kwak, I. Park, and J. B. Park, "Dynamic shear behavior of concrete-soil interface based on cyclic simple shear test," KSCE Journal of Civil Engineering, vol. 18, no. 3, pp. 787793, 2014.

[3] G. QG, Engineering Characteristics of Coarse-Grained Soil and Its Application, The Yellow River Water Conservancy Press, Zhengzhou, 1998.

[4] J. G. Potyondy, "Skin friction between various soils and construction materials," Geotechnique, vol. 11, no. 4, pp. 339353, 1961.

[5] Y. Zong-Ze, Z. Hong, and X. Guo-Hua, "A study of deformation in the interface between soil and concrete," Computers and Geotechnics, vol. 17, no. 1, pp. 75-92, 1995.

[6] L. M. P. Hu and J. Pu, "Testing and modeling of soil-structure interface," Journal of Geotechnical and Geoenvironmental Engineering, vol. 130, no. 8, pp. 851-860, 2004.

[7] L. D. Suits, T. C. Sheahan, G. A. Miller, and T. B. Hamid, "Interface direct shear testing of unsaturated soil," Geotechnical Testing Journal, vol. 30, no. 3, pp. 13301-14191, 2007.

[8] A. Taha and M. Fall, "Shear behavior of sensitive marine clayconcrete interfaces," Journal of Geotechnical and Geoenvironmental Engineering, vol. 139, no. 4, pp. 644-650, 2013.
[9] J. Wang, F. Y. Liu, P. Wang, and Y. Q. Cai, "Particle size effects on coarse soil-geogrid interface response in cyclic and postcyclic direct shear tests," Geotextiles and Geomembranes, vol. 44, no. 6, pp. 854-861, 2016.

[10] Y. Xiao and H. L. Liu, "Elastoplastic constitutive model for rockfill materials considering particle breakage," International Journal of Geomechanics, vol. 17, no. 1, article 04016041, 2016.

[11] B. Farhadi and A. Lashkari, "Influence of soil inherent anisotropy on behavior of crushed sand-steel interfaces," Soils Found, vol. 57, no. 1, pp. 111-125, 2017.

[12] K. Fakharian and E. Evgin, "Cyclic simple-shear behavior of sand-steel interfaces under constant normal stiffness condition," Journal of Geotechnical and Geoenvironmental Engineering, ASCE, vol. 123, no. 12, pp. 1096-1105, 1997.

[13] G. Yang, G. Li, and B. Zhang, "Experimental studies on interface friction characteristics of geogrids," Chinese Journal of Geotechnical Engineering, vol. 28, no. 8, pp. 948-952, 2006, (in Chinese).

[14] X. Chen, J. Zhang, Y. Xiao, and J. Li, "Effect of roughness on shear behavior of red clay-concrete interface in large-scale direct shear tests," Canadian Geotechnical Journal, vol. 52, no. 8, pp. 1122-1135, 2015.

[15] A. N. Aliyeh, L. Ali, and T. S. Piltan, "Influnence of particle shape on the shear strength and dilation of sand-woven geotextile interfaces," Geotextiles and Geomembranes, vol. 45, no. 1, pp. 54-66, 2017.

[16] Y. J. Ji, K. Jia, and Q. H. Yu, "Direct shear tests of freezing strength at the interface between cast-in-situ concrete and frozen soil," Journal of Glaciology and Geocryology, vol. 39, no. 1, pp. 86-91, 2017, (in Chinese).

[17] C. H. Li, G. Q. Kong, and H. L. Liu, "Study of temperaturecontrolled pile-red clay interface tests and stress-strain relationship," J. China Civil Engineering Journal, vol. 52, no. S2, pp. 89-94, 2019, (in Chinese).

[18] M. C. He, H. P. Xie, S. P. Peng, and Y. D. Jiang, "Study on rock mechanics in deep mining engineering," Chinese Journal of Rock Mechanics and Engineering, vol. 24, no. 16, pp. 28032813, 2005, (in Chinese).

[19] H. P. Xie, F. Gao, Y. Ju et al., "Quantitative definition and investigation of deep mining," Journal of China Coal Society, vol. 40, no. 1, pp. 1-10, 2015, (in Chinese).

[20] H. Kang, X. Zhang, L. Si, Y. Wu, and F. Gao, "In-situ stress measurements and stress distribution characteristics in underground coal mines in China," Engineering Geology, vol. 116, no. 3/4, pp. 333-345, 2010, (in Chinese).

[21] S. C. Li, H. P. Wang, Q. H. Qian et al., "In-situ monitoring research on zonal disintegration of surrounding rock mass in deep mine roadways," Chinese Journal of Rock Mechanics and Engineering, vol. 27, no. 8, pp. 1545-1 553, 2015, (in Chinese).

[22] J. C. Gu, L. Y. Gu, A. M. Chen, J. Xu, and W. Chen, "Model test study on mechanism of layered fracture within surrounding rock of tunnels in deep stratum," Chinese Journal of Rock Mechanics and Engineering, vol. 27, no. 3, pp. 433-438, 2008, (in Chinese).

[23] Y. G. Zhang, S. Y. Zhu, J. K. Tan, L. D. Li, and X. J. Yin, "The influence of water level fluctuation on the stability of landslide in the Three Gorges Reservoir," Arabian Journal of Geosciences, vol. 13, no. 17, p. 845, 2020.

[24] J. Guo, X. Liu, C. Qiao, and C. Xu, "Comparison of the simple shear property between dry and saturated sand under high 
stress," Journal of Beijing Jiaotong University, vol. 34, no. 1, pp. 69-72, 2008, (in China).

[25] L. I. U. Xiliang, Z. H. U. Weishen, and L. I. Shucai, "Testing study on interface shear properties under high pressure," Chinese Journal of Rock Mechanics and Engineering, vol. 23, no. 3, pp. 408-414, 2004, (in China).

[26] X. L. Liu, G. Y. Yu, and G. S. Zhao, "Experimental research on shear strength of interface under high pressure," JournalChina University of Mining and Technology-Chinese Edition, vol. 32, no. 1, 2003(in china).

[27] Y. Lu, Research on the Mechanical Behavior Evolution of Sand Shear Band and Sand-Structure Interface Layer under High and Low Pressure, China University of Mining and Technology, 2014.

[28] M. Uesugi and H. Kishida, "Frictional resistance at yield between dry sand and mild steel," Soils and Foundations, vol. 26, no. 4, pp. 139-149, 1986.

[29] M. Uesugi, H. Kishida, and Y. Tsubakihara, "Friction between sand and steel under repeated loading," Soils and Foundations, vol. 29, no. 3, pp. 127-137, 1989.

[30] J. H. Chen, J. S. Zhang, and J. Li, "Experimental research on mechanical characteristics of cohesive soil-structure interface by considering its roughness," Journal Sichuan University (Engineering Science Edition), vol. 47, no. 4, pp. 22-30, 2015.

[31] A. S. Vesic and G. W. Clough, "Behavior of granular materials under high stresses," Journal of the Soil Mechanics and Foundations Division, vol. 94, no. 3, pp. 661-688, 1968.

[32] JGJ55, "People's Republic of China national standard - specification for mix design of plain concrete," 2011.

[33] GB/T50107, "Standard for inspection and evaluation of quasiconcrete strength in People's Republic of China," 2010.

[34] JGJT23, "People's Republic of China national standardtechnical specification for concrete compressive strength by rebound method," 2011.

[35] X. L. Liu, Study on Stress of Shaft Lining in Unstable Formation of Deep Alluvium, Coal Industry Press, Beijing, 2004.

[36] X. L. Liu and J. Luo, "The affecting factors analysis on the shearing characteristic of the interface under high pressure," Journal of Shandong University (Engineering Science), vol. 33, no. 4, pp. 461-466, 2003.

[37] C. S. Desai and Y. Ma, "Modelling of joints and interfaces using the disturbed-state concept," International Journal for Numerical and Analytical Methods in Geomechanics, vol. 16, no. 9, pp. 623-653, 1992.

[38] Y. Liu and Y. H. Lu, "Large-scale simple shear tests of particle crushing of coarse-grained soil," Journal of Hohai University: Natural Sciences, vol. 37, no. 2, pp. 175-178, 2009.

[39] J. T. Dejong and G. G. Christoph, "Influence of particle properties and initial specimen state on one-dimensional compression and hydraulic conductivity," Journal of Geotechnical and Geoenvironmental Engineering, vol. 135, no. 3, pp. 449-454, 2009.

[40] J. D. Frost, G. L. Hebeler, T. M. Evans, and D. J. JT, "Interface behavior of granular soils," Engineering Construction and Operations in Challenging Environments, vol. 8, pp. 65-72, 2004.

[41] J. F. Wang, M. S. Gutierrez, and J. E. Dove, "Numerical studies of shear banding in interface shear tests using a new strain calculation method," International Journal for Numerical and Analytical Methods in Geomechanics, vol. 31, no. 12, pp. 1349-1366, 2007.
[42] G. Zhang, Study on Static Characteristics and Elastoplastic Damage Theory of Interface between Coarse Grained Soil and Structure, Tsinghua University, Beijing, 2002.

[43] P. V. Lade, J. Yamamuro, and P. A. Bopp, "Significance of particle crushing in granular materials," Journal of Geotechnical Engineering, vol. 122, no. 4, pp. 309-316, 1996.

[44] B. O. Hardin, "Crushing of soil particles," Journal of Geotechnical Engineering, vol. 111, no. 10, pp. 1177-1192, 1985.

[45] Ministry of Housing and Urban-Rural Development, People's Republic of China, GB50487-2008 Water Conservancy and Hydropower Project Geological Survey Specification, China Plan Press, Beijing, 2009.

[46] W. A. Hai-dong, L. I. Jian-wen, C. H. Xi, and L. Fang-cheng, "Dynamic characteristics of unsaturated remolded sandy soil through cyclic shear tests," Rock and Soil Mechanics, vol. 37, no. 11, pp. 3115-3312, 2016. 